\title{
Szkice
}

\section{Etnografia przedtekstowa. Fenomenologiczne korzenie interpretacji antropologicznej ${ }^{1}$}

Tomasz Rakowski
Tekst został przygotowany w ramach prac realizowanych w projekcie badawczym Narodowego Centrum Nauki nr 2012/05/D/HS2/03639 tnografowie prawie od samego początku, narodzin - metody badań terenowych zapisują elementy niejasnej jeszcze wiedzy, pojawiającej się podczas pracy w najróżniejszy sposób - na papierze, na dyktafonie, w fotografiach i filmach czy w pamięci. Dopiero później, na postawie skomplikowanych historii tworzą pierwsze zapiski, które następnie analizują w zaciszu gabinetu, by w końcu zbudować interpretację innego, cudzego życia. To właśnie z tym nie mógł pogodzić się Victor Turner ${ }^{2}$.

1 Niniejszy teskt powstał na podstawie wprowadzenia oraz mojego tekstu z tomu Pretextual Ethnographies. Challenging the Phenomenological Level of Anthropological Knowledge-Making, red. T. Rakowski, H. Patzer, Sean Kingston Publishing, Canon Pyon, 2018. Ponadto w niniejszym numerze "Tekstów Drugich" opublikowane zostają artykuły z tego tomu następujących autorek i autorów: Anne Line Dalsgård, Grzegorza Godlewskiego, Kirsten Hastrup, Andrew Irvinga i Heleny Patzer. Za zgodę uprzejmie dziękujemy wydawcy. Ponadto, osobny, oryginalny tekst przygotował do tego numeru Nigel Rapport.

2 V. Turner Od rytuału do teatru. Powaga zabawy, przeł. M. i J. Dziekanowie, Oficyna Wydawnicza Volumen, Warszawa, 2005.
Tomasz Rakowski etnolog, antropolog kultury, kulturoznawca, lekarz. Prowadzi badania w Polsce i w Mongolii. Adiunkt w Instytucie Etnologii i Antropologii Kulturowej UW, współpracuje z Instytutem Kultury Polskiej UW. Zajmuje się antropologicznymi badaniami ubóstwa, badaniami oddolnych procesów rozwojowych, antropologią sztuki współczesnej i partycypacyjnej, animacją kultury oraz najnowszą metodologią badań kulturowych. 
Pisał on - jak można zamykać czyjeś życie, formę nagromadzonych doświadczeń, w ramy „nieruchomego" tekstu? Był przekonany, że nadawanie źródłom etnograficznym formy tekstu jest co najmniej niewystarczające. Antropologiczne przedsięwzięcia zdają się w ten sposób "dotyczyć trupa” - pisał za D.H. Lawrence'em - podczas gdy powinniśmy koncentrować się przede wszystkim na „żywym mężczyźnie” i „żywej kobiecie”., Doszedłem do wniosku - pisał także Turner -że czytanie i komentowanie materiałów etnograficznych to za mało; powinniśmy je odgrywać"3.

Chciałbym tutaj zaproponować perspektywę metodologiczną, która pozwala w pewnym sensie na owo „odgrywanie" etnografii i która przede wszystkim łączy się z tym, co można by nazwać przedtekstowością w badaniach antropologicznych. Sama przedtekstowość jest tutaj rozumiana jako aktywne, ucieleśnione kształtowanie wiedzy, formujące się w postaci ciągu rozpoznań, wypełniające doświadczenie zdobywania wiedzy terenowej. Chciałbym pokazać, że tego typu zaangażowanie - wyraźnie fenomenologiczne - może być podniesione do poziomu metodologicznej samoświadomości. Kluczowym momentem jest tu proces budowania wiedzy za pomocą specyficznego, wytwarzanego w ciągu pracy narzędzia percepcyjnego (i w konsekwencji - ekspresyjnego), które pozostaje czynne i aktywne długo po zakończeniu samych prac terenowych. O ile zatem Malinowski postulował, by szukać „niewidzialnego faktu”, rozpoznawalnego dopiero w świetle metody funkcjonalnej ${ }^{4}$, ja chciałbym zaproponować taką perspektywę, w której poprzez to percepcyjno-ekspresyjne narzędzie ten „niewidzialny fakt" może zostać wydobyty i uchwycony w jego całej ucieleśnionej i ontologicznej mocy.

Nie jest to jednak proste. Zamiast logiki interpretacji opartej na tekście proponuję inny sposób, osiągalny za pomocą logiki działania i udziału - odgrywanie, poświęcanie uwagi, podążanie za aktorami i wydarzeniami, który można odnaleźć pod materialnymi, widocznymi danymi. Do takiej wiedzy dochodzi się poprzez rozpoznawanie "wydarzeń etnograficznych" i uczenie się wyczuwania nieustannie pojawiających się zjawisk, w różnych miejscach, w różnych terenach. Stopniowo tworzy się w ten sposób rodzaj milczącego, często niewidocznego, ale intensywnego doświadczenia. W związku z tym

3 Tamże, s. 147.

4 B. Malinowski The Method of Field-Work and the Invisible Facts of Native Law and Economics, w: tegoż Coral Gardens and Their Magic: A Study of the Methods of Tilling the Soil and of Agricultural Rites in the Trobriand Islands, Allen \& Unwin, London, 1935, t. 2, s. 317-340. 
należy szczególnie uważnie zbadać zdolność uczestniczenia w takiej rzeczywistości i znaleźć fenomenologiczne idiomy dla ucieleśnionego, „gęstego uczestnictwa", jak pisała Jaida Kim Samudra ${ }^{5}$ - co oczywiście jest trawestacją dobrze znanego, Geertzowskiego "gęstego opisu”. W tym sensie badania etnograficzne mogą być taką szczególną formą działania, która może być uznana za "dzieło" (zresztą tak, jak dzieje się w przypadku tekstów pisanych), tyle że w tym przypadku będzie to pewna niepisana historia rozumienia, która może być ujmowana jako droga kształtująca to, co zostaje w ostateczności zapisane - zaczynająca się bardzo wcześnie w terenie i pozostająca później w aktywności przez długie lata.

\section{Etnografia i zwroty metodologiczne: odzyskiwanie doświadczeń}

W ostatnich dwóch dekadach XX wieku metodologia antropologiczna przeszła przez „zwrot literacki” $\mathrm{i}$ cały paradygmat Writing Culture z lat 8o., które wprowadziły świadomość tworzenia bardzo „literackich" i „politycznych” reprezentacji badanych rzeczywistości kulturowych ${ }^{7}$. Wysiłki poczynione przez przedstawicieli tego kierunku pozwoliły uwolnić się od iluzji, że etnografia jest zaledwie aktem gromadzenia faktów lub mówionych relacji antropologia odkryła w ten sposób procesy retoryki etnograficznej. Do kolejnego aktu krytyki i przewartościowania wewnątrz tej dyscypliny doszło jednak już w kolejnych latach, wraz z pojawieniem się nowych znaczeń przestrzeni, powiązań i mobilności, co następnie spowodowało przekształcenie w ogóle sensu pojęcia terenu i pracy w terenie. Związana z tym rosnąca świadomość dotycząca dylematów etycznych pracy w terenie pomogła antropologii wydobyć na wierzch także dziedzictwo kolonializmu, ukryte nie tylko w piśmiennictwie, ale również w procesie tworzenia, komponowania i konstruowania terenu ${ }^{8}$. W związku z tym pojawia się też nieco inny sens

5 J.K. Samudra Memory in our Body: Thick Participation and the Translation of Kinesthetic Experience, "American Ethnologist” 2008 No. 35 (4), s. 665-681.

6 Zob. B. Scholte The Literary Turn in Contemporary Anthropology " Critique of Anthropology" 1987 Vol. 7 (1), s. 33-47.

7 Zob. J. Clifford, G. Marcus Writing Culture. The Poetics and Politics of Ethnography, University of California Press, Berkeley-Los Angeles-London, 1986.

8 Zob. A. Gupta, J. Ferguson Poza „kulturę": przestrzeń, tożsamość i polityka różnicy, przeł. J. Giebułtowski, w: Badanie kultury. Elementy teorii antropologicznej. Kontynuacje, red. M. Kempny, E. Nowicka, PWN, Warszawa 2006 , s. 267-283; zob. też V. Amit Introduction: Constructing 
etnografii, w którym praca w terenie umożliwiła antropologii rozpoznanie nowych źródeł napięć i w ogóle nierówności społeczno-ekonomicznych. Etnograficzni Inni mogą być więc już postrzegani jako współpracujący, negocjujący - także w sensie uznania moralnej dwuznaczności badania etnograficznego, np. podczas prowadzenia badań, które mogą być wykorzystane przez państwo czy globalne instytucje i korporacje międzynarodowe. George Marcus pokazał np., że akty interpretacyjne dotyczące obrazów wchodzenia i zanurzania się w lokalnej społeczności („gęsty opis”) mogą zawierać warstwy ironii, fikcji intymności i zupełnie różne cele, ukryte zarówno w działaniach etnografów, jak i ich "tubylców" . To Marcus a następnie kolejni badacze twierdzili, że nowe badania etnograficzne powinny obejmować analizę sieci sił politycznych i symbolicznych, kształtujących cele pracy terenowej antropologa, a także lokalne gospodarcze i polityczne determinanty („przymusy”) jego pracy. To w tym sensie teren został rozszerzony do etnografii wielostanowiskowej, i tym samym zaczął znacznie wykraczać poza wyobrażone miejsca ludzi „rdzennych”, „dalekich” lub „podporządkowanych”. Przez zmianę w myśleniu o związku antropologii z kolonializmem, zmieniła się też sama "scena” badań etnograficznych i zostały nakreślone nowe postaci „tubylców”, do których, jak zauważył Peter Pels ${ }^{10}$, zaliczają się przede wszystkim też sami antropologowie.

Miejsce badań antropologicznych przestaje być więc wyobrażane jako przestrzeń monolityczna, „gotowa do badań”, a „teren” coraz bardziej wydaje się również czymś bardzo biograficznym i politycznym. Wiąże się z nim proces tworzenia wzajemnych relacji, kontekstów i miejsc, nigdy nie jest natomiast czymś „czekającym na odkrycie”"1. W tej perspektywie proces

the Field, w: Constructing the Field: Ethnographic Fieldwork in the Contemporary World, ed. by V. Amit, Routledge, London 2000, s. 2-18; zob. też K. Hastrup, K. Fog Olwig Siting Culture. The Shifting Anthropological Object, London 1997; zob. też G. Marcus Użyteczność kategorii uczestnictwa w zmieniających się kontekstach antropologicznych badań terenowych, przeł. J. Jaxa-Rożen, w: Clifford Geertz. Lokalna lektura, red. M. Brocki, D. Wolska, Wydawnictwo Uniwersytetu Jagiellońskiego, Kraków 2003.; zob. też P. Pels What Has Anthropology Learned from the Anthropology of Colonialism?, "Social Anthropology" 2008 No. 16, s. 280-299.

9 G. Marcus Ethnography in/of the World System: The Emergence of Multi-Sited Ethnography, "Annual Review of Anthropology" 1995 Vol. 24, s. 95-117; G. Marcus Użyteczność kategorii... P. Pels What Has Anthropology Learned from the Anthropology of Colonialism?, "Social Anthropology" 2008 No. 16, s. 295.

11 V. Amit Introduction: Constructing the Field, w: Constructing the Field: Ethnographic Fieldwork..., s. 6. 
„tworzenia terenu” staje się otwarty, przypadkowy, plastyczny, przekracza wszelkie „zastane” czy „naturalne” powiązania między ludźmi, ale polega na nowych więzach pokrewieństwa, znajomości i zależności' ${ }^{12}$. Widać więc wyraźnie , że pojęcie „terenu badań” radykalnie się zmieniło i nie jest to już oczyszczane, lokowane, ukorzeniane przez antropologa miejsce -, że nie są to na ogół stabilne i przestrzennie czy czasowo spójne populacje $e^{13}$.To właśnie w tym miejscu warto jednak zastanowić się szczególnie nad miejscem antropologicznego "uczestnictwa” w życiu tych ludzi a w tym kontekście nad fenomenologiczną rolą uwagi w obliczu tego nowego, plastycznego i relacyjnego charakteru terenu. Vered Amit, kanadyjska antropolożka, sugeruje np., że nacisk na „zanurzenie" badacza w świecie innych ludzi może nawet wzmocnić efekt izolacji, stworzyć „dziwnie uporczywą bańkę izolacji”, tzn. usunąć z pola widzenia te wszystkie liczne konteksty rzeczywistości, które mogą być wykryte w nowych, „konstruowanych” terenach - diasporach, pasmach przemieszczeń, w ponadlokalnych i wirtualnych skupiskach interakcji ${ }^{14}$. Im bardziej jednak staje się jasne, że praca w terenie jest też przez antropologa wytwarzana i wypełniana jego zależnościami, „terenami” i działaniami (biografiami), tym bardziej chciałbym pokusić się jednak o zbudowanie fenomenologicznego i właśnie przedtekstowego obrazu korzeni tych produkowanych, współ-produkowanych i bardzo często efemerycznych środowisk, w których prowadzone są badania. Twierdzę, że jest to rodzaj etnograficznej konieczności. Wykrycie namacalnej rzeczywistości świata społecznego wraz z jego powiązaniami, doświadczeniem mobilności, „relacjami na odległość”, powiązaniami w obszarze szerszych nierówności i problemów społecznych jest po prostu konieczne, by ukazać etnografię jako realną i zawieszoną

12 Nawet samo słowo 'teren' [field - TR]' - jak pisał James Clifford - „przywołuje mentalne obrazy oczyszczonej przestrzeni, uprawy, pracy, gruntu". J. Clifford Praktyki przestrzenne. Badania terenowe, podróże i praktyki dyscyplinujące w antropologii, przeł. S. Sikora, w: Badanie kultury. Elementy teorii antropologicznej. Kontynuacje, red. M. Kempny E. Nowicka, PWN, Warszawa, 2006 , s. 139.

13 Co więcej, jego przestrzennie i czasowo ujęta forma jest produktem pewnego splotu procesów historycznych, politycznych, ekonomicznych i literackich, dających początek dyscyplinie poznania. Zamiast przedstawiać kultury jako pewne jednostki nierozerwalnie związane z miejscem lub grupą, rozwijana jest koncepcja badania procesów politycznych i historycznych poprzez praktyki kształtujące i wytwarzające takie jednostki jak "miejsce”, "lud" czy "społeczność".

14 V. Amit Introduction: Constructing the Field, w: Constructing the Field: Ethnographic Fieldwork..., s. 6. 
jednocześnie „W światowym systemie” napięć ekonomicznych, przepływów i nierówności ${ }^{15}$.

Takie fenomenologiczne badanie jest zatem jednocześnie próbą wyjścia poza zestandaryzowane użycia interpretacji: sięga ono bowiem po prostu inaczej do doświadczeń i relacji między ludźmi. Jest to raczej próba takiego wstrząśnięcia kontekstem czy wydarzeniem, aby nawet pozbyć się nieprawdziwych, ale bardzo nagromadzonych, codziennych użyć i sposobów rozumienia tego, co „inne”, ,tubylcze”, ,etniczne”. Jest więc aktem niezgody na nieodpowiedniość słów i doświadczenia, interpretacji i świata - stąd próby odtworzenia znaczeń gęstych, jakby wyostrzonych. Taka praca nad kształtowaniem się znaczeń ma na celu doprowadzić do bardzo trudnej, ale bardzo wyraźnej komunikacji - komunikacji, można rzecz ująć, bardziej „wyczyszczonej”. To zadanie rozumienia „w działaniu”, zadanie przekroczenia reguły języka, w którym napotykamy oczywistości, słowa jako gotowe matryce język taki, wszelkie domknięte interpretacje, teksty, tereny, mają bowiem tendencję, aby stać się, jak owe słowa, o których pisał Stefan Themerson, że „straciły kontakt z rzeczywistością, a emocjonalne wokoło nich aureole zaistniały same w sobie i uzyskały moc magiczną działania na nasze systemy nerwowe" ${ }^{16}$. Sztuka prowadzenia etnografii może więc, poprzez przywracanie znaczenia realnym, ludzkim doświadczeniom burzyć pewną retoryczną magiczność opisów, słów, wyobrażeń i stawać się nawet czymś w rodzaju „sztuki deziluzyjnej"17.

\section{To, co przedtekstowe}

Proponuję więc wrócić do procesów tworzenia tekstów etnograficznych, tym razem jednak nie na ich dekonstruowaniu (ujawnianiu ich retorycznych źródeł), jak było w tomie Writing Culture i słynnego seminarium w Santa Fe

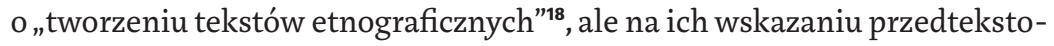
wych i w konsekwencji - fenomenologicznych - źródeł. Co jednak oznacza sam termin "przedtekstowy” $i$ jak wiąże się z fenomenologią? Zróbmy tutaj

15 G. Marcus Ethnography in/of the World System...

16 A. Karpowicz Kolaż. Awangardowy gest kreacji. Themerson, Buczkowski, Białoszewski, Wydawnictwa UW, Warszawa 2008, s. 99-100.

17 Tamże, s. 91-92.

18 J. Clifford, G. Marcus Writing Culture... 
krok wstecz do momentu „zwrotu literackiego”, obiektywizacji niektórych znaczeń i procesów kulturowych i ku lekturze kulturowych znaczeń zbudowanej przez Clifforda Geertza. Metafory czytania, tłumaczenia i pisania kultury eksplodowały (w sensie przede wszystkim krytycznym) właśnie po serii seminariów w Santa Fe i zaczęły z wielką siłą oddziaływać, tworząc nowe, postsemiotyczne ramy antropologii kulturowej. U źródła jest to jednak zwrot w stronę rozumienia relacji z doświadczanej realności kultury jako „odczytywania”, jako gęstego opisu znaczeń kulturowych, steoretyzowanego przez Geertza, w którym pierwsze całostki, wyłowione słowa, gesty, obrazy stają się znaczącymi (które zostaną później umieszczone w kontekście, po to aby zaczęły znaczyć zgodnie z opisywaną logiką kultury). James Clifford przedstawia ten proces następująco (rekonstruując proces „opisu gęstego" Geertza): z dyskursu czy wydarzenia powstaje tekst, a następnie test odczytywany jest w kontekście innych stekstualizowanych danych, „nie zapisane zachowania - pisze on - mowa, wierzenia, tradycja ustna i rytuał zostają oznaczone jako korpus, potencjalnie znaczący całokształt, wyodrębniony z bezpośredniej dziejącej się i płynnej substancji"19. I nieco dalej: „zapisane w postaci tekstu rytuał czy wydarzenie nie są już blisko związane z tworzącymi je konkretnymi aktorami"20, a ja bym dodał, że nie są już blisko z tworzącymi je działaniami i aktywnymi intencjami społecznymi. Widać tu, że Geertz, zanim jeszcze wprowadzi te wyodrębnione i wychwycone z wydarzeń „dane” w kontekst kulturowy, tworząc gęsty opis, już wstępnie jakby semiotyzuje rzeczywistość akcji, semiotyzuje też jej wymiar realny, ontologiczny. Utekstawia to, co pierwotnie nietekstowe. Dlaczego tak robi? Korzysta tutaj z precyzyjnych rozważań Paula Ricœura ${ }^{21}$ o działaniu znaczącym rozważanym jako tekst. Pokazuje, że to, co zostaje z wydarzenia mowy (wydarzenia dyskursu) czy z działania, to właśnie to, co się utrwala, co zostaje w mówieniu powiedziane albo co zostaje w działaniu zrobione. A zatem tu, w tym miejscu otwiera się przestrzeń do semiotyzacji i zarazem uchwycenia nietekstowej rzeczywistości jako znaczącej, zorganizowanej w tekst, w której kultura może być „odczytywana”. Ten jeden zabieg ma doniosłe konsekwencje. Krytyka tekstu może zatem narzucać reguły czytania rzeczywistości społecznej. Rzeczywistość społeczna może nabrać

19 J. Clifford Kłopoty z kulturq, KR, Warszawa 2000, s. 47.

20 Tamże, s. 47-48.

21 Zob. P. Ricœur Model tekstu. Działanie znaczq̨ce rozważane jako tekst, przeł. J. Falkowska, „Pamiętnik Literacki" 1984 z. 2. 
charakteru przedmiotu analizowanego i czytanego krytycznie, zgodnie z regułami sztuki - np. sztuki dekonstrukcji. Thomas Csordas pokazuje, że badacze kultury właśnie ten moment podchwycili i odtąd w wielu przypadkach sposoby rozumienia kultury rozumieli intuicyjnie jako jej „czytanie”22. I w tym miejscu proponuję cofnąć się o krok. Csordas we wstępie do pracy Embodiment and Experience. The Existential Ground of Culture and Self pokazuje bowiem, że jest taka możliwość, iż Geertz sam zsemiotyzował idee Ricœura, niejako wbrew intencjom samego autora, oraz że antropologowie podążali przede wszystkim za tym ruchem, interpretując później i „czytając” kultury. Jednocześnie, sugeruje on, że to właśnie w samym eseju Ricœura możemy znaleźć coś, co można by przypisać do rzeczywistości nietekstowej i niejęzykowej, a co zarazem ulega zapisowi i wytwarza to, co kulturowe. Kiedy zatem uważnie przyjrzymy się temu esejowi, zauważymy, że rzeczywiście Ricœur pokazuje, że nawet tekst - źródło, na którym pracuje wielu badaczy kultury - zdradza istnienie obszaru poprzedzającego jego powstanie. Tekst, jak już pokazano, chwyta „to, co powiedziane” w mówieniu. Zanim jednak to, co powiedziane, „znaczenie mówienia” wykształci się, wcześniej mamy już do czynienia z obecnością samej tej przedtekstowej rzeczywistości właśnie sfery przede wszystkim akcji i działania. Sam Ricœur przyjmuje, że zarówno w mówieniu, jak i w każdym innym działaniu jest coś, co zaczyna znaczyć, a co nie wyczerpuje się w znaczeniu językowym czy tekstowym; „bez wątpienia musimy przyznać - pisze - że akt perlokucyjny (akt działania) jest tym aspektem wypowiedzi, który najmniej daje się zapisać”23. I dalej: „przez znaczenie aktu mowy należy zatem rozumieć nie tylko zdanie w wąskim sensie aktu wypowiadania, ale także moc illokucyjną [performatywną „sprawczość” mówienia, np. rozkazu - przyp. T.R.], a nawet działanie perlokucyjne [...] w związku z tym nadaję tu słowu «znaczenie» bardzo szeroki zakres, który obejmuje wszystkie aspekty i poziomy intencjonalnej eksterytorializacji sprawiającej, że zapis wypowiedzi staje się możliwy"24. A zatem to, co „chwyta" badacz kultury, to owe „wszystkie aspekty i poziomy eksterytorializacji intencjonalnej”, pewna przestrzeń, z której rodzi się tekst. Wypowiedzi odnoszone są tu zarazem do samej sytuacji mówienia (wskazania ostensywne, tu i teraz rozmowy), jak i do pewnego głębszego

22 T. Csordas Introduction: The Body as Representation an Being-in-the World, w: Embodiment and Experience. The Existential Ground of Culture and Self, ed. by T. Csordas, Cambridge 2001, s. 11. 
kontekstu, zdradzającego cechy wiedzy ontologicznej, znajomości świata jako horyzontu doświadczenia (wskazania nieostensywne). Ricœur w swoim eseju podobnie postępuje z rozumieniem samego działania - część $\mathrm{z}$ niego utrwala się na podobieństwo zapisu, jednak to nie tylko znaczenie działań, gestów, akcji społecznej, które „przechodzą do historii”, ale ich samo działanie; można to rozumieć jako ową eksterytorializację działania i pewien „świat", który za nią stoi - ale świat rozumiany ontologicznie, a nie opisowo czy sytuacyjnie. Jest to właśnie pewien obszar odkrywania potencjalności tego eseju w rozpoznawaniu tego, co tekst poprzedza. Takie zapisy w formie tekstowej i zrazem odwołujące do tego, co należy do rozumienia działania (a nie jego interpretacji jako tekstu), antropolożka Rena Lederman nazwała "pretekstami dla etnografii"25, a więc elementami pamiętania działającej i zarazem rozumianej kultury. A zatem tak oto powstaje hasło - etnografia przedtekstowa.

Badacz wychwytuje więc przede wszystkim ,aspekty i poziomy zamierzonej eksterytorializacji" - pewnej przestrzeni, z której rodzi się tekst. Oświadczenia te odnoszą się zarówno do samej sytuacji mówienia (rozmowa „tu i teraz”), jak i do konkretnego głębszego kontekstu, i równocześnie zdradzają atrybuty wiedzy ontologicznej i znajomości świata jako horyzontu doświadczeń (projekty bycia w świecie). Esej Ricœura dociera właśnie podobnie do rozumienia działań jako takich - niektóre z nich są zachowane w formie zapisu, chociaż nie tylko znaczenie aktów, gestów i działań społecznych „tworzy historię”, ale również samo ich wykonywanie; może to być rozumiane jako eksterioryzacja działania lub jako pewnego rodzaju „świat”, który za nim stoi - świat nie w sensie opisowym czy sytuacyjnym, ale ontologicznym. Przede wszystkim mamy tu zatem do czynienia z rozszerzeniem pewnej sztuki widzenia i pojmowania rzeczywistości kulturowej - jest to pewnego rodzaju ukryta możliwość, którą można odnaleźć zarówno w tekście Ricœura, jak i w późniejszych badaniach etnograficznych. Sądzę zatem, że istnieje hermeneutyka działania, zgodnie z którą praktyki pojmowania i przywoływania zaistniałych "faktów" prowadzi do pracy fenomenologicznej uczestniczenia-rozumienia, co można przedstawiać nawet jako formę osobnego dzieła - podobnie jak tekst, esej, powieść, filmowy obraz czy teatralny i parateatralny spektakl.

25 R. Lederman Pretexts for Ethnography: On Reading Fieldnotes, w: Fieldnotes. The Makings of Anthropology, ed. by R. Sanjek, Cornell University Press, Ithaca-London 1990, s. 71-73. 


\section{Źródła poznania etnograficznego - wyjście poza kulturowe genealogie}

Poniżej chciałbym zaprezentować możliwości przedtekstowości - aby pokazać właśnie to, co poprzedza i jednocześnie tworzy tekst. Gdybym miał porównać przedsięwzięcie etnograficzne do twórczości literackiej - powróciłbym przede wszytkim do początków pisania i komunikowania potrzeb, pragnień, intencji, działań itd. Zamiast tego chciałbym jednak wskazać alternatywną drogę dla etnografii, a być może także i dla innych dyscyplin. Dlatego też uważam że pora inaczej spojrzeć na to, w jaki sposób zdobywa się wiedzę w terenie - otóż dzieje się to nie tylko poprzez interpretację opartą na tekście (hermeneutyka tekstu), ale również poprzez hermeneutykę działania, interpretację, która poprzedza i stanowi fundament aktów tworzenia tekstu etnograficznego (hermeneutyka działania).

Ten poziom prowadzenia badań terenowych trzeba jednak w jakiś sposób nazwać, ująć w słowa, chociażby tak, że odkrywa i ujawnia on nowe procesy, które można określić „tworzeniem umiejętności etnograficznych"26. Rozpoznanie tej techniki oznacza więc tworzenie pewnej metodologicznej świadomości i znalezienie języka, który mógłby ją przekazać. Kluczowym punktem jest więc ujawnienie i przekazanie strzępów wiedzy silnie związanych z wydobywaniem wiedzy i faktów podczas badań. Pewną wskazówkę można odnaleźć we wczesnych pracach Erica Havelocka i w jego Przedmowie do Platona ${ }^{27}$, w którym pisze on o Grekach epoki umysłów częściowo jeszcze przedpiśmiennych („homerycki stan umysłu”), będących w połowie drogi między „oralnym działaniem” a „krytycznym rozproszeniem”. Analiza przejścia z epoki Hezjoda i spontanicznego, ucieleśnionego mimesis do świata epoki piśmienności jest tu najważniejszym i najbardziej subtelnym punktem: poprzednicy Platona stali przed koniecznością wyrażania nowych słów i pojęć, tworzenia nowego świata abstrakcyjnych pojęć i słownika, który wcześniej nawet nie istniał. Staram się poprowadzić metodologię antropologiczną „Wzwyż” od tego procesu. Niemniej jednak muszę jednocześnie spoglądać „W dół" - na literacką metodę wykonywania etnografii - aby ujawnić inne źródło czynienia, działania lub mówienia oraz zdolność do tworzenia własnego, oryginalnego języka. Nie chcę tutaj wyróżniać żadnego medium - oralnego, literackiego, audiowizualnego czy innego. W ramach debaty o Wielkim Podziale nie podążam ani za pojęciem utopii słowno-cielesnej jako pierwotnej

26 M. Harris Introduction, w: Ways of Knowing. New Approaches in the Anthropology of Learning and Experience, ed. by M. Harris, Berghahn Books, Oxford 2007. 
ludzkiej rzeczywistości żywego słowa ${ }^{28}$, ani za Derridiańskim dążeniem do umiejscawiania cielesnych, spontanicznych aktów komunikacyjnych (takich jak krzyk czy lament ) w ramie zapisu znaku lingwistycznego ${ }^{29}$. Podążę raczej za twierdzeniem Kirsten Hastrup, że „nawet język praktykowany jest w rzeczywistości życia, za którym stoją motywacje i poza nią nie słyszy się go we właściwy sposób"30. Celem nie jest zatem dążenie do wyjaśnienia liniowej ewolucji mediów komunikacji, ale podążanie za praktyką etnograficzną i przeniesienie tej walki na wzorce postrzegania i wyrażania doświadczeń poza metodą interpretacji opartą na piśmie.

Tego rodzaju opis metodologiczny został bardzo jasno przedstawiony w krótkim artykule Tamary $\mathrm{Kohn}^{31}$ na temat poznania zasad rządzących napięciami kastowymi w społeczności Yakha w wschodnim Nepalu. Tamara Kohn pokazuje, że istnieją pewne przedwerbalne zdolności etnograficzne, które pozwalają nam zwracać uwagę na zdarzenia, słowa, gesty, działania ludzi itd. Są one, jak twierdzi Kohn, „ukryte w słowach, w ich najsubtelniejszym znaczeniu, jakie tylko jesteśmy w stanie wychwycić lub na nie zareagować, ponieważ, jako ludzie, jesteśmy głęboko zaangażowani we wzajemne relacje" ${ }^{\text {"32 }}$. Pokazuje ona pewną wrażliwość, którą wykształcili u siebie etnografowie, by dostrzec uczucie zbrukania podczas relacji z sąsiadami z niższej kasty. Jako przykład (dwa fragmenty notatek terenowych) przytacza swoje wczesne zaangażowanie w życie Yakha, kiedy to dzięki temu, że zwracała uwagę na barwę głosu, wyczuwała frustracje i niepokoje swoich gospodarzy, mogła później zrozumieć działania: „Na tym przykładzie pragnę pokazać - konkluduje - że byłam w stanie wyobrazić sobie głębię znaczenia, które sugerowały czyny i słowa Sharady, tylko dlatego, że znacznie wcześniej miałam bardzo emocjonalną i poruszającą rozmowę z Kamalą i Amą na temat kast. Gdybym nie miała tego wcześniejszego doświadczenia, prawdopodobnie nie przywiązywałabym aż tak dużej wagi do

28 Zob. W.J. Ong Oralność i piśmienność. Słowo poddane technologii. tłum. J. Japola, Wyd. WUW, Warszawa, 2011.; zob. też J. Goody The Domestication of The Savage Mind, Cambridge University Press, Cambridge 1984, oraz The Logic of Writing an the Organization of Society, Cambridge University Press, Cambridge 1986.

29 J. Derrida, O gramatologii, tłum. B. Banasiak, Warszawa: Wydawnictwo KR, Warszawa 1999... K. Hastrup,. Droga do antropologii. Między doświadczeniem a teoriq, przeł. E. Klekot, WU), 2008 Kraków., s.6o ce \& Anthropological Knowledge, ed. by K. Hastrup, P. Hervik, London 1994, s. 13-27. 
późniejszego zdarzenia"33. Ten proces - pisze dalej Kohn - to „coś nieznanego", ta ,jakość kultury, którą zapewne mimowolnie poznałam przed wszystkimi innymi", może być z powodzeniem uważana za sposób zauważenia tych „wczesnych" sposobów zdobywania wiedzy. Już sam proces sporządzania notatek może być opisany jako ciąg spostrzeżeń: to bardziej sporządzanie rejestru gęstych "mentalnych notatek", headnotes, jak nazwał je Simon Ottenberg ${ }^{34}$, które mogą stanowić kluczowy moment dla zrozumienia tego, co przedtekstowe. Jak pokazuje Judith Okely, w pewnym sensie są one medium przekształcającym zapamiętany i ucieleśniony zapis doświadczania w zapis tekstowy/słuchowy i vice-versa, jako że wskazują one na (i jednocześnie ożywiają) proces tworzenia wiedzy podczas sporządzania notatek, prowadząc „od ucieleśnionych wspomnień do tworzenia tekstu"35. Tak więc, w poszukiwaniu szczególnej umiejętności „bycia w terenie", wychwytywania szczegółów, rozumienia kontekstów i działań, mogę mieć do czynienia z wyjątkową pracą twórczą. To Rena Lederman nazwała takie cząstki elementarne wiedzy właśnie „przed-tekstami etnografii". Te na poły eksperymentalne i na poły tekstowe zapisy, jakby zapisy-wpisy-rysunki, tworzące się z powstającej wiedzy, były więc nie tyle "gęstym opisem", ile raczej "gęstym pamiętaniem", choć to one przecież odgrywają najważniejszą rolę w dyscyplinowaniu myśli czy interpretacji. Co więcej, jak pisze Lederman, „są niebezpieczne”, stanowią zawsze „wyzwanie dla pamięci”36. Etnografia przedtekstowa może być zatem rozumiana, tak jak i ja to pojmuję, jako coś, co pozostaje aktywne podczas pisania, filmowania, nagrywania, a nawet prowadzenia wykładu; podobnie działa ona jak pamięć: coś, co często jest nieumyślne lub niereferencyjne, a co w wielu przypadkach wykracza poza bezpośrednią świadomość podmiotów. Judith Okely pokazywała właśnie, w podobny sposób, że „notatki terenowe mogą mieć formę zapisu dowodów, dosłownych cytatów, a nawet danych ilościowych; ale mogą one również działać jako wyzwalacz catkowitego doświadczenia"37.

33 Tamże, s. 17-18.

34 Zob. S. Ottenberg Thirty Years of Fieldnotes. Changing Relationship to the Text, w: Fieldnotes. The Makings of Anthropology ed. by R. Sanjek, Ithaca and Cornell University Press, London 1990.

35 J. Okely Fieldwork Embodied, "Sociological Review” 2007 Vol. 55, s. 77.

36 R. Lederman Pretexts for Ethnography: On Reading Fieldnotes, w: Fieldnotes. The Makings of Anthropology, s. 73.

37 J. Okely Knowing without notes, w: Knowing how to know. Fieldwork and The Ethnographic Present, ed. by N. Halstead, E. Hirsch, J. Okely, Seria EASA, Berghahn Books, New York-Oxford 2008 , s. 55-75. 
Ciąg tworzenia "mentalnych notatek” (headnotes) to zatem pewien ciąg spostrzeżeń wpleciony w bieg czasu - pamiętanie, kształtowanie wspomnień i pojmowania, działania w teraźniejszości. Dlatego też sam proces interpretacji rozpoczyna się bardzo wcześnie - tak, jak to zostało opisane w pracy Kohn. Jest zatem wręcz nasączony ucieleśnionym, fenomenologicznym budowaniem wiedzy i uczeniem się za pomocą zmysłów, ale po pewnym czasie staje się niemal niesłyszalny, a nawet autonomiczny, badacze terenowi przestają być go świadomi. Anthony Cohen w artykule poświęconym zapamiętywaniu interpretacji w czasie prowadzenia badań pokazywał natomiast, że proces kształtowania idei i samego rozumienia jest długotrwały i wciąż napędza zmiany w percepcji etnografa poprzez „innych kąt widzenia, inny dostęp"38. Podąża tu jednocześnie za myślą Simona Ottenberga, „w tym sensie - pisał Ottenberg - doświadczenie w terenie się nie kończy. Notatki terenowe, które kiedyś odczytywałem w pewien sposób, teraz odczytuję zupełnie inaczej"39. Jeszcze inny antropolog, Anthony Cohen, określił ten proces jako po prostu niewidzialny „post-fieldwork fieldwork”, czyli „ pewien wewnętrzny i dynamiczny proces przepracowywania bezgłośnej i niewidzialnej wiedzy, zinternalizowane życie własnych mentalnych notatek [headnotes]”., Chodzi tu o to - pisze dalej - że analiza i literatura antropologiczna polegają na tym, że nasze mentalne notatki (headnotes) właściwie nadal się rozwijają i budują dopiero naszą wiedzę jeszcze długo po tym, jak przestajemy ludzi obserwować i z nimi rozmawiać" ${ }^{40}$. To w tym sensie można zatem chyba najpełniej pojmować termin przedtekstowy: używany jest on do oznaczenia wiedzy rodzącej się w trakcie badania etnograficznego i w warunkach „społecznej zażyłości", zapisywanej w gęstych notatkach terenowo-pamięciowych, co zawiera w sobie też pewien uwewnętrzniony ciąg kształtowania się i „wykuwania" spostrzeżeń etnograficznych (to zatem jakby niewidzialny brat-bliźniak pisania).

Spontaniczne sporządzanie notatek w terenie prowadzi w ten sposób do takiego rozumienia, które może w pewnym stopniu wymknąć się spod kontroli zarówno etnografa, jak i ludzi, z którymi ten pracuje. O czym to jednak właściwie świadczy? Co to właściwie pokazuje? Po pierwsze, okazuje się, że etnograf „wie coś więcej”, niż jest w stanie zapisać, wypowiedzieć - jest

\footnotetext{
38 A. Cohen Post-Fieldwork Fieldwork, "Journal of Anthropological Research" 1992 Vol. 48, s. 339.

39 S. Ottenberg Thirty Years of Fieldnotes...

A. Cohen Post-Fieldwork Fieldwork..., s. 345.
} 
to więc też moment, który pokazuje, że mamy do czynienia z jakby nadmiernym nagromadzeniem wewnętrznej wiedzy (przedtekstowość ujawnia się tutaj jako „poznanie w działaniu”). Pamiętanie zapisków typu „headnotes” nie tylko ożywia "gęste uczestnictwo" (thick participation) i ucieleśnioną wiedzę, ale także umożliwia nam zarejestrowanie czegoś, co wyjściowo dotyczy jakby innej ontologii. W "headnotes” chodzi bowiem nie tyle o zapis, ile bardziej o intensywny akt posiadania, wiedzy, który rodzi się, jak można by się wyrazić, poprzez powstanie „etnograficznego dublera” - czyli wewnętrznego, żywego procesu zapamiętywania, który wykracza poza bezpośrednią świadomość etnografa. Simon Ottenberg nazwał „headnotes” raczej „siłą napędową" wiedzy terenowe ${ }^{41}, \mathrm{w}$ pewnych momentach etnografowie nie są bowiem w stanie spisać tej najbardziej intensywnej części wiedzy. Z jednej strony rodzi się to poczucie blokady , ,nie potrafię spisać wiedzy, w czasie jej doświadczania”, pisała Judith Okely ${ }^{42}$, z drugiej - to tu właśnie gromadzi się nadmiar wiedzy i zrozumienia, nadal aktywny, nieustannie angażujący ciało, pamięć, interpretację i jednocześnie coś, co Fabian nazywał „non-referential memory".

\section{Przedostać się poza powierzchnię opisu: to, co przedtekstowe i fenomenologiczne}

Wyzwanie polega zatem na zbudowaniu nowego rodzaju etnografii i języka etnograficznego, nawet jeśli mamy wyjściowo do czynienia z opisową i interpretacyjną tendencją odcieleśnionego sposobu obserwacji. Paul Stoller dość dawno już pisał w Sensuous Scholarship, że chce podjąć wysiłek, by wyjść poza tekst, odzyskując zmysłowe przestrzenie w antropologii, „próbę, by obudzić na nowo ciało uczonego" "43. Nawet jeśli ciało powszechnie pojawia się w dyskursach akademickich od lat 8o. XX wieku, często jest, jak twierdzi Stoller, wyrażane za pomocą specyficznego języka: „Po pierwsze, nawet najbardziej przenikliwi twórcy uważają ciało za tekst, który można czytać i analizować. Ten analityczny zabieg ogołaca ciało z jego zapachów, smaków, faktur i bóli jego zmysłowości. Po drugie, najnowsze teksty na temat ciała są najczęściej

41 S. Ottenberg Thirty Years of Fieldnotes..., S. 147.

42 J. Okely Anthropology and Autobiography: Participatory Experience and Embodied Knowledge, w: Anthropology and Autobiography, ed. by J. Okely, H. Callaway, London 1992, S. 17. 
wyrażane za pomocą zastanawiająco odcieleśnionego języka"44. Ta próba odzyskania zmysłowości w etnografii trwa już dość długo - i nie polega tylko na konstruowaniu gatunku literackiego, ale na nowych doświadczeniach etnograficznej wizualności i tym, co znajdujemy w ostatnich badaniach na temat zmysłów i praktyk sensorycznych ${ }^{45}$. W etnografiach przedtekstowych zmysłowość i ucieleśnienie są jednak przede wszystkim sposobem pogłębiania realności opisu i rozumienia, można je sobie wyobrazić jako moment przebudzenia, jako chwilę, w której tożsamość człowieka jest - słowami Rolanda Barthes'a (odnoszącymi się do Dramatu Petera Sollersa) - „niczym drapieżny ptak, unoszący się wysoko ponad snem, w którym spokojnie zajmujemy się naszym prawdziwym życiem, naszą prawdziwą historią; kiedy się budzimy ptak już nas przygniata, i to właśnie wtedy, gdy opada, zanim nas dotknie, trzeba go uprzedzić i mówić" 46 . Taka etnografia polegałaby zatem wręcz na odwróceniu aktu pisania - i przesunięciu się o krok w kierunku intensywnego "gromadzenia" rozumienia.

Tutaj przechodzę jednak już do drugiego filaru przedtekstowości, czyli do fenomenologicznego zaplecza antropologicznej pracy. Zwrot ku podejściu fenomenologicznemu i rozpoznaniu ucieleśnionego, empirycznego fenomenologicznego sensu w „faktach”, w „wydarzeniach” jest już długo rozwijany - przykłady tworzenia tych form rozumienia obecne w niedawnych monografiach i nieco dawniejszych już pracach antropologów, takich jak Thomas Csordas ${ }^{47}$, Robert Desjarlais ${ }^{48}$ i Michael Jackson ${ }^{49}$; istnieją również

44 Tamże, s 14

S. Pink Doing Sensory Ethnography, Sage, London 2009, zob. też R. Cox, A. Irving, C. Wright Beyond Text: Critical Practices and Sensory Anthropology, Manchester University Press, Manchester 2016.

46 R. Barthes Dramat, poemat, powieść, przeł. K. Kłosiński w: Lektury, tegoż, Wydawnictwo KR, Warszawa. 2001., s. 33

T. Csordas Introduction: The Body as Representation an Being-in-the World, w: Embodiment and Experience...; tegoż Embodiment and Cultural Phenomenology, w: Perspectives on Embodiment. The Intersection of Nature and Culture, ed. by G. Weiss, H.F. Haber, Cambridge University Press, London-New York 1999.

R. Desjarlais Shelter Blues, University of Pennsylvania Press, Philadelphia 1997.

M. Jackson Path Towards a Clearing. Radical Empiricism and Ethnographic Inquiry, Bloomington 1989; T. Csordas, Introduction: The Body as Representation...; K. Hastrup Droga do antropologii...; M. Jackson Minima Ethnographica: Intersubjectivity and the Anthropological Project, University of Chicago Press, Chicago 1998; M. Jackson Existential Anthropology. Events, Exigencies, and Effects, Berghahn Books, Oxford 2008. 
badania nad intersubiektywnością i „procesową ontogenezą" Christiny Toren $^{50}$; nad teoretycznym ujęciem fenomenologii w praktyce etnograficznej Jasona Throopa i Keitha Murphy'ego ${ }^{51}$, Alessandro Duranti ${ }^{52}$ i Thorstena Giesera $^{53}$; badania nad osobistymi pracami terenowymi Judith Okely ${ }^{54}$ i Jaidy Kim Samudry ${ }^{55}$; prace nad metodologią Kirsten Hastrup ${ }^{56}$, prace Tima Ingolda dotyczące postrzegania środowiska i procesów „robienia” wiedzy ${ }^{57}$ oraz prace metodologiczne zebrane w tomach wydanych przez Marka Harrisa ${ }^{58}$, Narmalę Halstead, Erika Hirscha i Judith Okely ${ }^{59}$. Należy też wreszcie wspomnieć o zupełnie bieżącym, wciąż rozwijanym zwrocie fenomenologicznym, jak to ujął Orvar Löfgren ${ }^{60}$ pisząc przede wszystkim o próbach „ożywienia tradycji fenomenologicznej, jak np. w przypadku bardziej przyziemnych perspektyw postfenomenologii, usiłującej przybliżyć tradycję filozoficzną do badań nad codziennymi czynnościami poprzez rozwijanie etnografii". Aby jednak bardziej szczegółowo opisać to przejście, związek przedtekstowego i etnograficznego - z fenomenologicznym, należy też dokładniej wyjaśnić, w jaki sposób fenomenologiczna wiedza może być rozpoznawana, zauważana i utrwalana

50 C. Toren Intersubjectivity as Epistemology , "Social Analysis” 2009 Vol. 53 (2), s. 130-146.

51 C. J. Throop, K.M. Murphy Bourdieu and Phenomenology. A Critical Assessment, "Anthropological Theory" 2002 Vol. 2 (2), s. 185-207; C. J. Throop Articulating Experience , "Anthropological Theory” 2003 Vol. 3(2), s. 219-241.

52 A. Duranti, Husserl, Intersubjectivity, and Anthropology, "Anthropological Theory" 2010 Vol. 10 (1-2), s. 16-35.

53 T. Gieser Embodiment, Emotion and Empathy. A Phenomenological Approach to Apprenticeship Learning , Anthropological Theory” 2008 vol. 8 (3), s. 299-318.

54 J. Okely Fieldwork Embodied...

55 J.K. Samudra Memory in our Body...

56 K. Hastrup Droga do antropologii...; K. Hastrup, P. Hervik (ed.) Social Experience \& Anthropological Knowledge, London 1994.

57 T. Ingold Perception of the Environment. Essays on Livelihood, Dwelling and Skill, Routledge, London 2000, tegoż, Making: Anthropology, Archaeology, Art, and Architecture. Routledge, London 2013.

58 M. Harris Introduction...

59 N. Halstead, E. Hirsh, J. Okely (ed.) Knowing How to Know. Fieldwork and the Ethnographic Present, Berghahn Books, Oxford 2008.

60 O. Löfgren The Black Box of Everyday Life. Entanglements of Stuff, Affects, and Activities, "Cultural Analysis" 2014 Vol. 13, s. 78. 
za pomocą różnych rodzajów pojawiających się „danych”, kształtując, a nawet wydając na świat wiedzę antropologiczną ${ }^{61}$.

Sądzę jednak, że dużym problemem będzie tu częste rozumienie perspektywy fenomenologicznej jako próby spojrzenia „poza” formy światów kulturowych i historycznych. Subiektywność takiej perspektywy (rozumienie bardziej „naturalne”, które de facto jest „kulturowe"62 - ma być przezwyciężona przez „fenomenologiczną redukcję” - tak jak to pokazywał Edmund Husserl w swoich wczesnych pracach, a później już przez mniej radykalny zabieg „epoché”, wzięcie w nawias tego, co się pojawia. Za podstawę tego aktu budowania wiedzy poprzez epoché można by uznać oczyszczenie widzenia ze społeczno-kulturowej specyfiki na rzecz „perspektywy filozoficznej"; jednak, biorąc pod uwagę antropologiczne pragnienie zdobywania wiedzy o Innym, można powiedzieć, że jest to punkt, w którym może się pojawić pewna niebezpieczna fikcja pełnego, idealnego wglądu w badany świat społeczny i właśnie - świat Innego. Tutaj napotykamy zatem pewną pułapkę samej koncepcji „doświadczenia Innego”, związanej ze specyfiką tradycji fenomenologicznej, będącej nieodłączną częścią dyskursu głębi, autentyczności i wewnętrzności, który powstawał w trakcie rozwoju europejskich dyskursów literackich (dającą początek istnieniu tendencji do naturalizowania doświadczenia jako osobistego, wewnętrznego lub autentycznego ${ }^{63}$. To w tym miejscu właśnie Pierre Bourdieu ${ }^{64}$ rozpoczynał swoją krytykę fenomenologii, jednak koncentrując się szczególnie na Husserlu. Pokazał, jak Husserl, usiłując ujawnić czysty akt posiadania wiedzy, błędnie wziął za pewnik struktury posiadania wiedzy i postrzegania siebie i świata

61 Patrząc z dzisiejszej perspektywy można jednak zauważyć, że etnografie przedtekstowe można by również osadzać w szerszych ramach metodologicznych poszukiwań i nowych szkół w badaniach terenowych, które pojawiły się po rewolucji Writing Culture i poczuciu kresu pewnego eksperymentu metodologicznego. To zatem próba pojawiająca się razem z innymi poszukiwaniami, szkołami spod znaku Science and Technology Studies, z dążeniami do prowadzenia badań zaangażowanych i "badań w działaniu”, badań wiążących sztukę współczesną z antropologią, czy ostatnio ze zwrotem ontologicznym, przekraczającym epistemologie i skłaniającym się ku zaawansowanym konceptualnym i eksperymentalnym formom wiedzy antropologicznej, zob. M. Holbraad, M.A. Pedersen The Ontological Turn. An Anthropological Exposition, Cambridge University Press, Cambridge 2017. Zob. A. Duranti Husserl, Intersubjectivity...

63 Zob. R. Desjarlais Shelter...; C.J. Throop, K.M. Murphy Bourdieu and Phenomenology. A Critical Assessment, "Anthropological Theory” 2002 Vol. 2 (2), s. 17.

64 P. Bourdieu Outline of a Theory of Practice, Cambridge University Press, Cambridge 1977. 
jako „apodyktycznie pewne"65. Stąd fenomenologia (wraz z aktem redukcji) wydaje mu się raczej naiwna, nie rozpoznaje bowiem wintegrowanych w percepcję struktur społecznie konstruowanego, nieświadomego świata. Bourdieu przeczuwał - pisali Throop i Murphy - „że fenomenologia była niedoskonała, ponieważ nie zgłębiała, jak przeżyte doświadczenie powstawało dzięki dialektyce internalizacji uprzednio eksternalizowanych [hierarchicznych - przyp. T.R.] struktur społecznych"66. Ujmując rzecz krótko, metoda fenomenologiczna jest krytykowana przynajmniej z trzech powodów: że przypisuje sobie kategoryczny wgląd w podstawy wiedzy; że nie docenia społecznie skonstruowanych sfer "ja” i wreszcie - że tworzy fikcję intymnego, wzajemnego porozumienia z Innym.

Ponieważ są to poważne zastrzeżenia, choć dotyczące często zresztą bardzo uproszczonego sensu tego, co fenomenologiczne, chciałbym przedstawić tutaj bardziej zniuansowaną i szczegółową koncepcję etnografii już nie tylko jako wiedzy przedtekstowej, ale raczej jako aktywności etnograficzno-fenomenologicznej (fenomenologiczna metoda śledzenia zdarzeń, działań, doświadczeń i ucieleśnionych znaczeń). Podążam tu w dużym stopniu za pracą Alessandro Duranti, Husserl, Intersubjectivity, and Anthropology ${ }^{67}$, który dowodzi, że w podejściu Husserla intersubiektywność nie jest procesem zdobywania perspektywy Innego, ale jest to raczej możliwość posiadania wiedzy, pozycja na samym początku drogi, umożliwiająca interakcję. Zatem fenomenologiczna intersubiektywność to $w$ tym ujęciu konieczność uznania ruchów i intencji Innego, nawet poza spotkaniem twarzą w twarz. To szczególne doświadczenie „uczestnictwa w działaniu i odczuwaniu innej istoty, jednocześnie nie stając się tą inną istotą" ${ }^{\text {, }}$, to dla Husserla nic innego, jak ruch z jednego miejsca - do miejsca należącego do Innego; to jedynie chwilowe przesunięcie znaczeń, światopoglądów i praktyk: „początkowa koncepcja Husserla - pisze Duranti - ma znacznie szerszy zakres i nie wymaga osiągnięcia wspólnego

65 C.J. Throop. K.M. Murphy, Bourdieu and Phenomenology..., S. 189-193; zob. też P. Bourdieu Szkic teorii praktyki poprzedzony trzema studiami na temat etnologii Kabylów, przeł. W. Kroker, Wydawnictwo Marek Derewiecki, Warszawa 2007. Por. M. Pancewicz-Puchalska Praktykowanie kultury przez ciało. O pewnych watkach fenomenologicznych socjologii Pierre'a Bourdieu, w: Kultura jako kultura, red. I. Topp, K. Łukasiewicz, Wydawnictwo Uniwersytetu Wrocławskiego, Wrocław 2011, s. 141-145.

C.J. Throop, K.M. Murphy, Bourdieu and Phenomenology..., S. 190.

67 A. Duranti Husserl, Intersubjectivity...

68 Tamże, s. 22. 
porozumienia lub wzajemnego zrozumienia. W zamian, na poziomie interakcji, intersubiektywność według Husserla wskazuje na przyjęcie pewnej perspektywy, którą najlepiej charakteryzuje metafora «wymiany [handlowej] miejsc» [trading places] niż samo «rozumienie» [Innego - przyp.T.R.]"69.

Pojmowany właśnie w ten sposób proces intersubiektywności - jako trudna, ale możliwa droga, a nawet konieczna droga epistemologiczna - została jednak dostosowana do potrzeb badań antropologicznych w pracach Michaela Jacksona ${ }^{70}$ i Christiny Toren ${ }^{71}$. Michael Jackson opisał intersubiektywność jako dążenie do doświadczania własnego świata, przy jednoczesnym pozostawaniu w relacji z życiem i światem innych ludzi - co jest nie tylko niełatwe, ale i bywa niemożliwe. „Współudział i konflikt”, pisze więc Jackson, „to uzupełniające się bieguny intersubiektywności"72. W tej perspektywie intersubiektywność nie zdobywa pełnego dostępu do czyjegoś świata - jest to raczej miejsce, w którym pojawia się chociażby taka możliwość, w procesie wymiany między „ja” a „ty”, co angażuje umiejętność słuchania, rozumienia i przebudowania wspomnień. Toren nazwała to procesem „autopojezy”. „Dzieje się tak, ponieważ - pisze Toren - każda istota ludzka - w tym ja i ty - jest w każdym dowolnym momencie dynamicznym, autopojetycznym produktem własnej historii, $\mathrm{w}$ tym historii jego lub jej relacji z innymi"73. W tym ujęciu intersubiektywność nie polega zatem w żaden sposób na przyjmowaniu czyjejś perspektywy, ale raczej na zmiennej i nieustającej reorganizacji świata w celu rozumienia Innego; prowadzi nas to - jak pisze Toren - do „konkluzji, że możemy radykalnie się mylić co do siebie nawzajem, albo być pełnymi empatii i zrozumienia, tudzież uprzedzeń lub wręcz głupoty"74. Jest to właśnie sfera interpretacji, która jest zanurzona w działaniu, w „gęstym uczestnictwie” i należy koniecznie podkreślić, że zdobyta wiedza nie jest efektem jakiegoś empatycznego poznania, ale właśnie bardziej owej aktywnej, pamiętanej „wymiany miejsc"75. Taki sposób zdobywania wiedzy

69 Tamże, s. 29.

70 M. Jackson Minima Ethnographica..

71 C. Toren Intersubjectivity as Epistemology, "Social Analysis” 2009 Vol. 53 (2), s. 130-146.

M. Jackson Minima Ethnographica..., s. 4

C. Toren Intersubjectivity as Epistemology..., s. 136.

74 Tamże, s. 136. 
przypomina już ciąg aktywnych („headnotes”), jak to ujął Simon Ottenberg76, które mają zdolność „pokonania pamięci” i dyscyplinowania idei, spostrzeżeń i wspomnien' ${ }^{77}$.

Problem polega jednak cały czas na tym, że to ucieleśnione, milczące i dynamiczne działania podejmowane przez podmioty społeczne można uznać za procesy niemal bezwarunkowe i automatyczne, w których jesteśmy kulturowo uwięzieni i z którymi jesteśmy po cichu zaznajomieni. Jest to - w pewnym sensie - stanowisko Pierre'a Bourdieu, zgodnie z którym społecznie skonstruowane cielesne dyspozycje wpływają na postrzeganie, na działania, na cielesne praktyki, inaczej kształtowane w różnych kulturowych i społeczno-hierarchicznych światach. W tym sensie można dojść do wniosku, że akty cielesne, zawieszone w habitusie, są jakby nieświadome i w jakiś sposób pozbawione wszelkiego pośrednictwa: są umieszczone poza zasięgiem „świadomości” podmiotu. Jaida Kim Samudra pisze, że w ten sposób Bourdieu w dużym stopniu łączy jednak „dyskurs ze świadomością, a następnie zakłada, że te cielesne doświadczenia, które nie są wypowiedziane, pozostają w nieświadomości"78. Podobnie Jason Throop i Keith Murphy, w pracy dotyczącej parafenomenologii Bourdieu, wskazują, że jego perspektywa implicite promuje taką koncepcję uspołecznionego podmiotu, w której wszystkie "nie-dyskursywne treści świadomości są całkowicie poza naszą świadomą kontrolą"79.

Problem polega jednak właśnie na tym, by odnaleźć takie etnograficzne uczestnictwo, które oznaczałoby rozpoznanie czegoś zupełnie innego. Można zauważyć, że przeciwnie, nawet najistotniejsze i niedyskursywne (a nawet kontrdyskursywne) doświadczenia mogą być odczuwane, kierowane, pożądane i odzwierciedlane zarówno przez etnografa, jak i obiekty badawcze ${ }^{80}$. Możemy zatem stwierdzić, że etnografia jest zapisem ucieleśnionego i intersubiektywnego doświadczenia, obecnego w przekształceniach doświadczanego, badanego świata i w owej „,wewnętrznej drodze" badacza, w ciągu pracujących nieustannie headnotes, razem ze wszystkimi ich „przeszłymi działaniami” $i$,przyszłymi celami” (Dilthey, Turner), aureolami „protencji i retencji” (Husserl), „refleksji

\footnotetext{
76 Zob. S. Ottenberg Thirty Years of Fieldnotes...

77 R. Lederman Pretexts for Ethnography...

78 J.K. Samudra Memory in our Body..., s. 666.

79 C.J. Throop, K.M. Murphy Bourdieu and Phenomenology..., s. 198.

80 Zob. tamże, s. 199.
} 
i działania" (Schütz) ${ }^{81}$. Można w ten sposób powiedzieć, że taki proces rozwija się zatem nie tyle poprzez interpretację jakiegoś materiału społecznego etnograficznego, ile przede wszystkim przez budowanie i coraz pełniejsze używanie czegoś w rodzaju owego autonomicznego i autorskiego narzędzia percepcyjnego, etnograficznego „dublera” - cielesnego, interpretacyjnego organu ${ }^{82}$. Jednak to tu właśnie, mam wrażenie, pojawia się kluczowy moment wychwycenia pewnej początkowej formy rozumienia, zapamiętywania, prób zapisania - a przez to uczynienia z niej pre-tekstu etnografii. Jak to jednak rozumieć? Aby to pełniej wyjaśnić, posłużę się myślą Thorstena Geisera, który w pracy Embodiment, Emotion and Empathy. A Phenomenological Approach to Apprenticeship Learning ${ }^{83}$ zajmuje się koncepcją wiedzy budowanej poprzez „praktyki czeladnicze” - pewnej wiedzy, którą nazwałbym właśnie przedtekstową. Czeladnik, pokazuje w swoich analizach Geiser, uczy się od swego nauczyciela podążać za jego ontologicznym horyzontem i tak jak on angażować się w otaczające go środowisko. Dla czeladnika, ucznia, to podążanie jest więc czymś takim jak używanie laski przez niewidomego - przedmiotu, który umożliwia mu „dotykowe widzenie”. Laska ta nie jest jednak w tym przypadku przedmiotem, jest raczej sposobem komunikowania się ze światem. Jej działania, ruch, gesty (poruszającego się niewidomego) wyznaczają w ten sposób charakter otoczenia. Używając swej laski, niewidomy nie traktuje jej zatem w żaden sposób jak przedmiot, ale jak rodzaj "różdżki”, która wydobywa dla niego (kulturowy) świat. Stąd właśnie i badacz kultury, na podobieństwo niewidomego, podąża, poprzez „praktyki czeladnicze”, za swymi rozmówcami. Zaczyna wtedy po jakimś czasie posługiwać się nową „różdżką" - nowym sposobem widzenia świata - używa swej nowej umiejętności widzenia, wziętej w dużej mierze od swych rozmówców i tak właśnie dotyka i widzi, za pomocą swego nowego narzędzia. Wprowadza w ten sposób to narzędzie - swój nowy świat percepcyjny i świat Innego - do swojego własnego, dotychczasowego uniwersum, naciskając na nie i przekraczając je.

Jeśli zatem należy pomyśleć raz jeszcze o specyfice badań antropologicznych, to powstaje ona, zaczyna się i kończy w momencie, kiedy bliskość i zaangażowanie badacza zaczynają przemieniać poznawany świat - jest „wyczuwalny", a to znaczy, że stawia pewien „opór". Jest to próba rozpoznania realnego miejsca, w którym to, co „kulturowe”, za każdym razem się formuje, nabiera dopiero swoich cech, zaczyna więc, odkształcając wszelkie wypracowane,

\footnotetext{
$81 \quad$ C.J. Throop Articulating Experience...

82 Zob. także M. Harris Introduction..., s. 17.

83 Zob. T. Geiser, Embodiment, Emotion and Empathy..., s. 310.
} 
gotowe ujęcia. Ten proces rozumienia nie jest zatem w żaden sposób formą stabilną. Może on dotykać nieprzewidywalności i takiego doświadczenia, które, jak to ujął Hans-Georg Gadamer, , jest zawsze negatywne [...] doświadczenie, jeśli jest godne tej nazwy nigdy nie spełnia naszych oczekiwań" ${ }^{84}$, ,jest stale zagrożone" - pisał podobnie Michael Jackson ${ }^{85}$. Mogę pójść o krok dalej i stwierdzić, że w tej sytuacji aktorzy stają twarzą w twarz z nieprzewidywalnością procesów intersubiektywności („proces autopojezy nie jest samowolny", pisała wprost Christina Toren ${ }^{86}$ ) Wiedza etnograficzna ustępuje pod presją innego świata, a jest to świat „rozdygotany”, niedomknięty, pełen rozłącznych i zrazem spójnych percepcji, „pęknięć i szwów”, jak pisał Throop - i jako taki wymagający nieustannej, ucieleśnionej, pracującej „w tyle głowy” uwagi.

\section{„Korzenie inności"}

W sumie można by zatem powiedzieć, że antropologiczna praktyka fenomenologii wymaga przede wszystkim działającego, doświadczającego ciała, ciała „podatnego na zranienie”. Jaida Kim Samura pisze np. wprost, że taka praktyka „jest wiedzą cielesną zapisaną w ciele antropologa, która dopiero później zostaje uzewnętrzniona jako dane wizualne lub tekstowe, na potrzeby analizy"87. Etnografia może być zatem - podobnie jak chciał Turner - nawracającym momentem poznania i wykorzystania naszych ciał w inny sposób. Należy pamiętać, że nie znaczy to, iż trzeba poruszać się poza strefą języka - te elementy wiedzy "pracują” właśnie przy pisaniu, interpretowaniu, mówieniu, pracują jeszcze długo po zakończeniu pracy. Gdybym miał ponownie przeanalizować specyfikę badań antropologicznych jako działania, mógłbym powiedzieć, że zaczyna się ona i kończy w chwili, gdy intymność i zaangażowanie badacza powodują dokładnie to, że zaczyna się przekształcać obserwowany „świat”, który stawia w ten sposób pewien „opór”, staje się "namacalny".

Niniejsze opracowanie - i zmiany w antropologii, które pragnie zaproponować - to zatem próba określenia rzeczywistego miejsca, w którym to, co

\footnotetext{
84 H.-G. Gadamer Prawda i metoda. Zarys hermeneutyki filozoficznej, przeł. B. Baran, Inter Esse, Kraków 1993, s. 331.

85 M. Jackson Existential Anthropology...

86 C. Toren Intersubjectivity as Epistemology..., s. 136.

87 J.K. Samudra Memory in our Body..., s. 667.
} 
kulturowe, jest kształtowane wciąż na nowo, tworząc się, kształtując się nowe pola rozumienia i odkształcając wszelkie najbardziej rozwinięte, gotowe antropologiczne koncepcje.W tym sensie etnografia może też, podobnie, działać tak, jak działają kreatorzy, twórcy - ale w znaczeniu ludzi zręcznych, umiejętnych, „robiących” (to poeci, od greckiego czasownika poiein, tj. robić) swą sztukę zgodnie z jej pierwotnym rozumieniem - jako pewnego „czynienia”, *ar - pisał o tym Stephen Tyler w pracy Writing Culture - w językach indoeuropejskich było rdzeniem słownym oznaczających właśnie zharmonizowane działanie, sztukę „robienia”( stąd np. słowa zarówno art, jak i rite). To w tym sensie nauki etnograficzne stają się w ten sposób próbą działania, próbą rozumienia poprzez rozproszenie opisywanej rzeczywistości i niejako ujmowanie jej zawsze od nowa, pozwalając powracać badaczowi do bezpośredniego zmysłowego kontaktu z rzeczywistością. Od nowa zatem „umocowują” słowa i opisy, co wiąże się właśnie z pewną etnograficzną uwagą, która staję się dość poręcznym, ale i trudnym narzędziem rozumienia tego, co się wydarza ${ }^{88}$.

Nacisk na na proces kształtowania się pierwszych form zrozumienia, "ucieleśnionego narzędzia percepcji” jest więc związany z ujawnieniem procesów pracy antropologicznej, które przybliżają nas do światów wytwarzanych i doświadczanych przez innych ludzi ${ }^{89}$. Jednak oznacza to jednocześnie

88 Inspiracją jest tu także praca Agnieszki Karpowicz o awangardowych praktykach twórczych u Stefana Themersona, Leopolda Buczkowskiego i Mirona Białoszewskiego. Jak pokazuje Karpowicz, poprzez kolaż różnych mediów i ich użyć - w eksperymentach, których słowa stawały się znakami drukarskimi, dźwięki pojawiają się w próbach fonetycznych - wywoływane są nowe zdarzenia, przemieniające właśnie sam sposób funkcjonowania w świecie. Karpowicz odwołuje się tu do koncepcji gatunków mowy Michaiła Bachtina - a więc realnego działania, a nie tylko słownego kreowania - i pokazuje, że eksperymentowanie i nagromadzenie nowych użyć to bowiem takie miejsce, w którym słowa nie tyle wychodzą poza nawias ludzkiego doświadczenia, ile właśnie wracają z powrotem, ze zdwojoną energią; taka sztuka - pisze Karpowicz - która "konstruuje nowy język literacki oraz wizualny, która próbuje na nowo ustalać relacje między człowiekiem, techniką i naturą, jest próbą dotarcia do świata w bezpośrednim, zmysłowym kontakcie z jego materią". Ta perspektywa powrotu do - niespodziewanie - dialogowej i konkretnej (ukorzenionej w kontekście) obecności, powoduje że się w ogóle zmienia perspektywa spojrzenia na pracę etnograficzną, szczególnie w nowych, nieustannie rozpraszanych i konstruowanych terenach, A. Karpowicz, Kolaż..., s. 56-57.

89 Podobnie można rozumieć postulaty Johannesa Fabiana z Time and the Other. Jeśli mamy unikać angażowania innych istnień jako obiektywnej, zesencjonalizowanej przeszłości („kultury") - twierdzi Fabian - to powinniśmy stworzyć procedurę, która mogłaby zerwać wewnętrzne, czasowe dystanse w etnografii. „Efektywne badanie empiryczne - pisze wprost - jest możliwe tylko wtedy, gdy badacz i jego badani dzielq ze sobq czas", J. Fabian Time and the Other. How Anthropology Makes Its Object, New York 1983: Columbia University Press, s. 71. 
właśnie odkrycie tych procesów, które przybliżają nas do światów tworzonych i doświadczanych przez samych etnografów; stąd rozpoznanie tego, co przed-tekstowe, pozostaje jedynie punktem wyjścia dla całego przedsięwzięcia.

\section{Abstract}

\section{Tomasz Rakowski}

UNIVERSITY OF WARSAW

Pretextual Ethnography: The Phenomenological Roots of Anthropological Interpretation

Rakowski discusses how pretextual knowledge is produced in anthropological studies. Pretextuality is mainly understood as an active process, an embodied formation of knowledge that takes shape as a series of recognitions filling the ethnographical experience as it emerges in the research field. Thus instead of the logic of interpretation that is based on the practice of 'thick description' Rakowski proposes an interpretation through the logic of action, related to the practice of 'thick participation' and at the same time to the creation of a chain of headnotes. Rakowski also reconstructs attempts to build a second pillar of pretextual ethnography, i.e. the collection of phenomenological idioms referring to embodied field experience and at the same time to the permanently deforming anthropological understanding.

\section{Keywords}

pretextual ethnography, thick participation, headnotes, phenomenology, ethnographical experience 